\title{
ADVERTISING WITH SOCIAL DISCOURSE AS A BRAND POSITIONING TECHNIQUE: REVIEW OF RESEARCH WITH SPECIAL REFERENCE TO THE LATVIAN MEDIA
}

\author{
Aivars Helde ${ }^{1}$
}

\begin{abstract}
This study examines the nature of the social discourse of advertising used as a brand positioning technique. The focus is on consumer advertising that is directed at the promotion of selected products or services to the general public. The study is neither meant to exhaust all aspects of this particular discourse, nor present the answers to all the problems posed. The aims of this paper include analyzing varying commercial advertisements (both product/non-product ads) to investigate the intentions and techniques of consumer product companies for reaching more consumers and selling more products. Norman Fairclough's '3-D model' and Kress and van Leeuwen's 'grammar of visual design' present methods for use by professionals in this respect, but we focus on the use of stereotypes in our study.

Traditionally, stereotypes are defined as patterns or schemes by which people organize their behaviors and activities. Psychologists have been extremely interested in the persuasion techniques used by advertisers. The implicit question that most of these studies have entertained is whether advertising has become a force that molds cultural mores and individual behaviors, or whether it constitutes no more than a 'mirror' of deeper cultural tendencies within urbanized contemporary society.
\end{abstract}

The one thing which everyone agrees upon, is that advertising has become one of the most recognizable and appealing forms of social communication to which everyone in society is exposed.

However, it could be said from the results of this study that the producers of ads generally use power and ideology to change people's behavior and thoughts. In cases where 'old' stereotypes were effective, there was no attempt to change the consumer's habits, but rather the power of the ad was in preserving their customary behaviors. This is achieved through reinforcing behaviors known to be similar to the traditional values identified by customers. When we considered gender stereotypes we looked at notions about the supposedly traditional behaviors of men and women, and the characteristics and standards of these behaviors, which are grounded in our culture and society. Producers use these ideas to make customers feel they belong in the society, and become psychologically involved, in the story presented by the advertisement. Culture involves human values, actions, patterns, ideas, and material and artificial surroundings that enable interaction among people. The content of culture determines the particular qualities of certain groups of people, which potentially governs their consumer characteristics. This indicates the importance of understanding the way in which culture affects individuals. In today's information area, the media are the primary means of transmitting and reproducing cultural information. Today's media shape the image of culture in people's consciousness.

Finally, this study provides an analysis of varying ads, using different means of interpretation. All materials are taken from Latvian media.

UDC Classification: 304, DOI: http://dx.doi.org/10.12955/cbup.v3.615

Keywords: Social discourse analysis, stereotypes, brand, customer behavior, print advertisement, Fairclough-3D, Kress and van Leeuwen's grammar, Gestalt psychology.

\section{Introduction}

As the elements of the marketing program come together to create the complete offering, marketers must also consider how the marketing program will be used to create effective branding and positioning.

While the concept of a brand may seem relatively simple to understand, a branding strategy can actually be quite complex. From a technical point of view, a brand is a combination of name, symbol, term, or design that identifies a specific product. Brand has two parts: the brand name and the brand mark (Ferrell \& Hartline, 2012). The brand name is the part of a brand that can be spoken, and includes words, letters and numbers (e.g. Laima, KDF, and 7-up). The brand mark includes symbols, figures, and a design, which are the part of the brand that cannot be spoken (e.g. Nike's swoosh). Professor Jenni Romaniuk from the Ehrenberg-Bass Institute says: "Distinctive assets are the branding elements that uniquely identify the brand across the vast majority of category buyers, such as the Nike Swoosh or the red and

\footnotetext{
${ }^{1}$ Aivars Helde, lecturer, RISEBA University, Riga, Latvia, awhelds1@inbox.lv
} 
yellow M\&Ms. The opportunity and challenge of distinctive assets is that potential assets can come from a wide source of possibilities, from colors, fonts, advertising style, celebrities, characters or logos - just to name a few."

While these technical aspects of branding are important, a branding strategy involves much more than developing a clever brand name or unique brand mark. Good brands are those that immediately come to mind for a customer when they need a problem solved or a need fulfilled. So true is the saying, "the battle for your mind" (Ries \& Trout, 2001).

However, for most people advertising is something that encourages or persuades individuals to buy a special product. Yet, advertisements can do much more than this. As stated by Cook (1992), advertisements "also amuse, inform, misinform, worry, though it may be argued that these function are all in the service of the main function". Additionally, there are non-product advertisements that advocate change in behavior over promotion of products. These non-product ads, which are used in differing campaigns, show the effects of advertising without adopting the advocated behavior. As Cook (1992) states, "Ads may not always be obliged to refer to a product, but they are still obliged to refer, however obliquely, to a change of behavior".

Currently, the contemporary approach is to use a third possibility, which is to combine the above techniques in a way that promotes the product to different cultural and behavioral stereotypes. The aim of this advertising strategy is not to change an individual's habits or behavior but rather to maintain and strengthen them.

Advertising is involved in our everyday lives. It mirrors society and portrays a meaning and a message. Its social significance has led people to consider it as a type of discourse. Cook (1992) also remarks that "advertising is not a remote and specialized discourse, but a prominent discourse type in contemporary society."

Discourse has been described by (Gee, 2005) as "language (oral or written) in use with more sociopolitically oriented meaning". Fairclough (1989) goes further to define it as "just a particular form of social practice" that centers on power and ideology, which in turn influence and interact with each other. In other words, while discourse constitutes social practice, social practice also constitutes discourse (Wodak, 1997).

Intertextuality has been described "as texts [which] are recognized in terms of their dependence on other relevant texts" (Hatim \& Mason, 1990). Essentially, it amounts to the relationship between text and various languages or signifying practices of a culture. As well, it refers to those texts that articulate the cultural possibilities. Therefore, one reason for the success of an advertisement (or commercial) may well be the underlying relationship between its presentation and a literary association that is familiar to the target audience.

Interestingly, Rayport (2013) suggested that "Standard ad messaging and conventional creative executions and placement are rapidly becoming outmoded. To win consumer's attention and trust, marketers must think less about what advertising says to its targets and more about what it does for them".

\section{Problem Statement and Objective}

Many advertising studies tend to isolate the components of ads, concentrate on one or a few of these, but then ignore the rest. Also, there are some traditional theories, such as Fairclough-3D, and Kress and van Leeuwen's visual grammar, that while being suitable for use by students and researchers, are impractical for use by customers. 
The success of ads can be described using three basic parameters: strategy, creativity, and fabrication. The use of strategy: specific target selection, the target audience's choice, report creation and media planning, is very understandable and clear. However, describing advertising in terms of discourse is more complex and difficult. Also, it must be borne in mind that there is a danger of dilution with an analysis that attempts to tackle too much.

Professionals advise marketers to approach this advertising medium as a landscape that is composed of four domains: the public sphere, where we move from one place or activity to another, both online and off; the social sphere, where we interact with and relate to one another; the tribal sphere, where there are web affiliates with groups that define or express our identity; and the psychological sphere, where we connect language with specific thoughts and feelings (Rayport \& Jaworski, 2005). We will try to focus on local Latvian ads, with social discourse as a principle of brand communication with customer, associated with customer cultural habits and expectations.

\section{Social Responsibility and Advertising}

The traditional view of marketing considers ethics and social responsibility as suitable additions to business activities, though not necessarily essential. Today, it appears that ethical behavior does not only enhance a company's reputation, but also contributes significantly to its bottom line (Maignan, Gonzalez-Padron, Tomas, Hult, \& Ferrell, 2011; Nooyi, 2007).

Carroll (1991) states that "Social responsibility is a broad concept that relates to an organization's obligations to maximize its positive impact on society while minimizing its negative impact. Social responsibility consists of four dimensions: economic, legal, ethical, and philanthropic".

If a company chooses to ignore their social responsibility, they may lose their customers' trust. Subsequently, firms are increasingly incorporating ethics and social responsibility into their strategic marketing plan to not only deal with threats of increased regulations, but also to respond to customers' demands.

Often, firms profess to be socially responsible, while in reality their advertising comprises a marketing trick. As inferred by De Bono (1985), it is not easy to know where is the line is drawn between real and pretense in terms of social responsibility.

Accordingly, ads can be explained using a meaningful discourse. One method involves encoding/decoding as described by Hall (1973).

The term 'encoding' describes the process of producing a message and 'decoding' is about the reception and how the receiver makes sense of the encoded message. As stated by Hall (1973), "In the advertising discourse, for example, we might say that there is almost no 'purely denotative' communication. Every visual sign in advertising 'connotes' a quality, situation, value or inference which is present as an implication or implied meaning, depending on the connotation reference."

This theory can be used to analyze the type of discourse that clearly identifies the implicit ideologies behind these ads.

However, for better image analysis, as researchers we can also use the method described by Fairclough (1995) and later developed by Kress \& van Leeuwen (1996), which is well known as 'visual grammar'.

As Kress \& Van Leeuwen (1996) states "We take the view that language and visual communication both realize the same more fundamental and far-reaching systems of meaning that constitute our cultures, but that each does so by means of its own specific forms, and independently".

Fairclough (1995) developed three-dimensional boxes. The inner box contains the text, the middle box the discourse practice, and the outer one the socio-cultural practice. In printed advertisement these yield multimodal messages. 
Kress \& van Leeuwen (1996) define visual discourse, by way of two components: represented participants and interactive participants. The 'represented participants' are the people or things that are mapped on an image, while the 'interactive participants' are the producers and viewers. Relationships exist among all these participants. The relationships among the represented participants can be considered as syntactic, between the represented and interactive participants as sematic, and among interactive participants as pragmatic.

However, even though people mindlessly absorb the messages promulgated constantly by advertisements (which may have some subliminal effects on behavior), media images are only accepted, by and large, if they suit people's established preferences. It may be more accurate to say that advertising produces images that reinforce people's lifestyle models. Advertisers are not innovators. They are more intent on reinforcing lifestyle behaviors than in spreading commercially risky innovations. In this sense, advertisements are not in themselves disruptive of the value systems of the cultural mainstream; rather, they reflect shifts already present in popular culture. Furthermore, if they are really psychologically effective, it is primarily because they tap into deep-ingrained mythical and metaphorical structures of the mind (Johnson-Laird, 2004; Mothersbaugh, Huhmann, \& Franke, 2002).

\section{'Schemas' and commercial advertising with social discourse}

It is no exaggeration to claim that, today, most of our information, intellectual stimulation, and lifestyle models come from, or are related to, advertising images. This is an era in which advertising messages have moved away from describing the product in itself to focusing on the consumer of the product; creating product imagery with which the consumer can easy identify. Today we can say that ads and commercials offer the same kinds of promise and hope to which religions and social philosophies once held exclusive rights, like: security against the hazards of old age, better positions in life, popularity and personal prestige, social advancement, better health, and happiness. Marketers are pushing the advertising boundaries. Different companies have fueled the growth of so-called native content, creating both text and video that complement commercial messaging and encourage consumers to engage with it because it's more than an advertisement. Such advertising is conspicuously different from the conventional sort. In the best cases, it has editorial integrity and engages through relevance and value. But no matter how worthwhile your message, competing for attention, simply by shouting louder across the proliferating array of media platforms, is not a sustainable strategy. "If human experience is a medium for advertising, how can marketers engage consumers there in way they will welcome?" (Rayport, 2013). Rather than focusing first on communication strategy and marketing mix, producers should begin by considering how consumers live their lives and under what circumstances they will prove receptive to messages in this domain.

For analysis in this study, advertisements were selected as either product ads or non-product ads. Since the aim of this study was to open the 'ideological curtain' to see the power and ideology behind the images, the chosen ads are more visually relevant than textual. In other words, they communicate predominantly through images and pictures.

The advertisements in this study are from Latvian media with the brand promotion obtained through social discourse.

The dimensions of discourse and discourse analysis can be described in terms of these positions:

1. Text description
a. representing
b. relating 
c. identifying - as a position for text analysis

2. Discursive practices (analysis/interpretation) - as a position for processing

3. Social practices (social analysis/explanation)

So, we can define the first dimension as text analysis or description, the second dimension as processing analysis or interpretation, and the third dimension as the social analysis or explanation. All dimensions are interdependent and therefore the analysis can start with any of these components.

\section{Material}

Four different advertisements, product ads and non-product ads, were selected for analysis. Since the aim of the study was to open the 'ideological curtain' to see the power and ideology behind the images (Kelly, Lawlor, \& O'Donohoe, 2009), the chosen ads have greater visual content than textual; that is, the chosen advertisements communicate through images and pictures. These advertisements were: "For a real childhood", "Help put your baby in the world", "It makes no sense to live longer", and "Motorcyclist's summer."

\begin{tabular}{|l|l|}
\hline Figure 1: "For a real childhood" campaign by Laima (a candy manufacturer) \\
\hline Selgg \\
\hline Source: Author
\end{tabular}

Here we have a picture of a baby in a hammock. The colors used in this ad are blue, white and yellow. The color blue invokes peace, while the color yellow provides contrast. The color white embellishes the image of the baby and so attracts the viewers' attention so as to invite them to buy the biscuits shown below the baby. Above the picture of the baby are the words, in white: "For a real childhood, Selga." The company, Laima, is the producer of this ad, which appears to show the company as a socially responsible one that cares about children. The discourse of this ad is about a product that could be considered as supporting a charitable cause. Therefore, the viewer has the power to choose the biscuits or not. There is no sense of obligation.

This is a picture of a happy family, comprising a mother, a father and a baby. The company, Elvis, is the producer of this ad. There is no text, because this is a picture from a booklet. The colors in this advertising are light, with the accent being on a baby-pale bluish-green towel, a man kissing a woman, and the woman kissing the baby. The viewer almost feels too intimate with the family. On the booklet below is written: "Help put your baby in the world." This ad suggests a charitable purpose and alludes to trying to solve a problem. As a result, the viewer has the power to be involved or not. There is no power in the above to obligate the viewer to act. 
CBU INTERNATIONAL CONFERENCE ON INNOVATION, TECHNOLOGY TRANSFER AND EDUCATION MarCh 25-27, 2015, Prague, CZECH RePublic

\begin{tabular}{|l|l|}
\hline Figure 2: "Help put your baby into the world" campaign by Elvis (a store chain) \\
\hline Source: Author
\end{tabular}

Figure 3: Channel 3 TV commercial under the campaign "It makes no sense to live longer" about pet abandonment

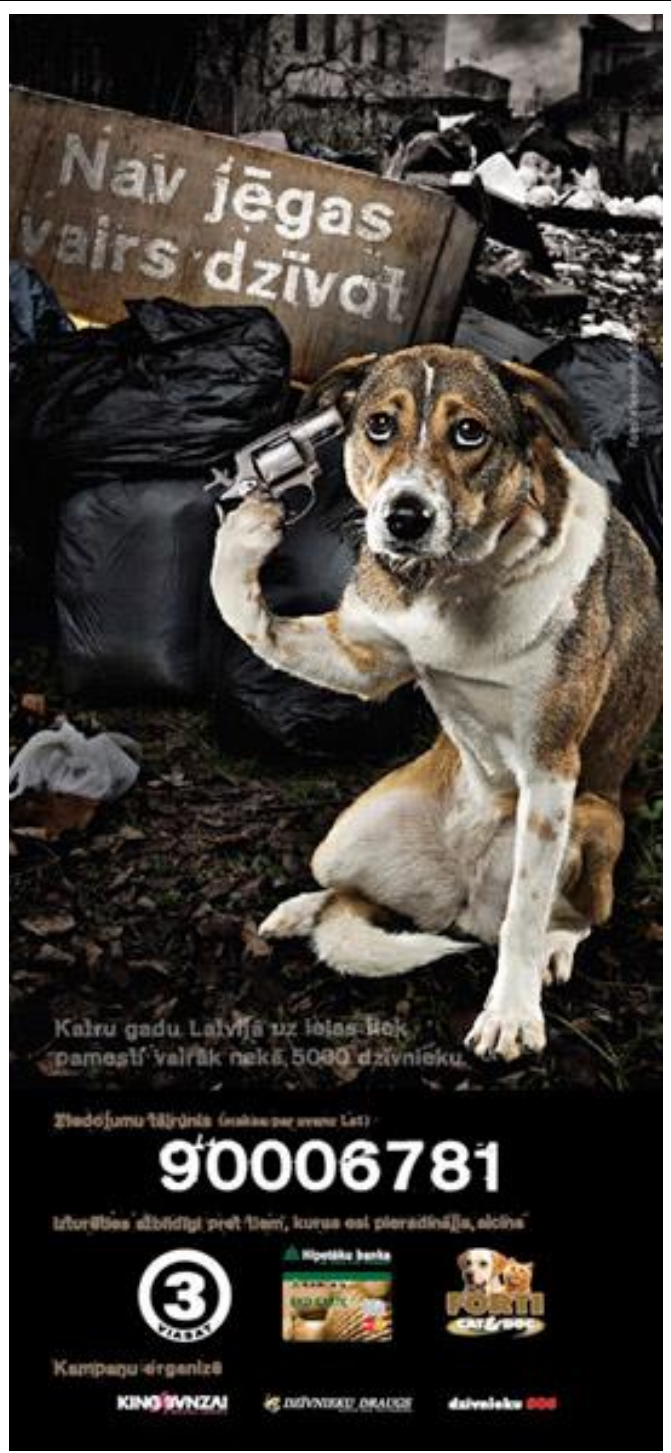

Source: Author 
This is a non-product ad. As a result, its discourse is about social responsibility, to highlight a social problem. The colors in this advertisement are dark and gloomy, with only a picture of a dog, which is somewhat bright. The producer of this advertisement is TV Channel 3. In the picture, the dog has aimed a gun to his head and behind, on a box, are the words "It makes no sense to live longer." This ad draws attention towards a problem. The eye level angle shows the power balances on the side of viewer. The viewer can feel there are tragic results of not looking after pets. As a result, the viewer feels compelled to obey the advertisement.

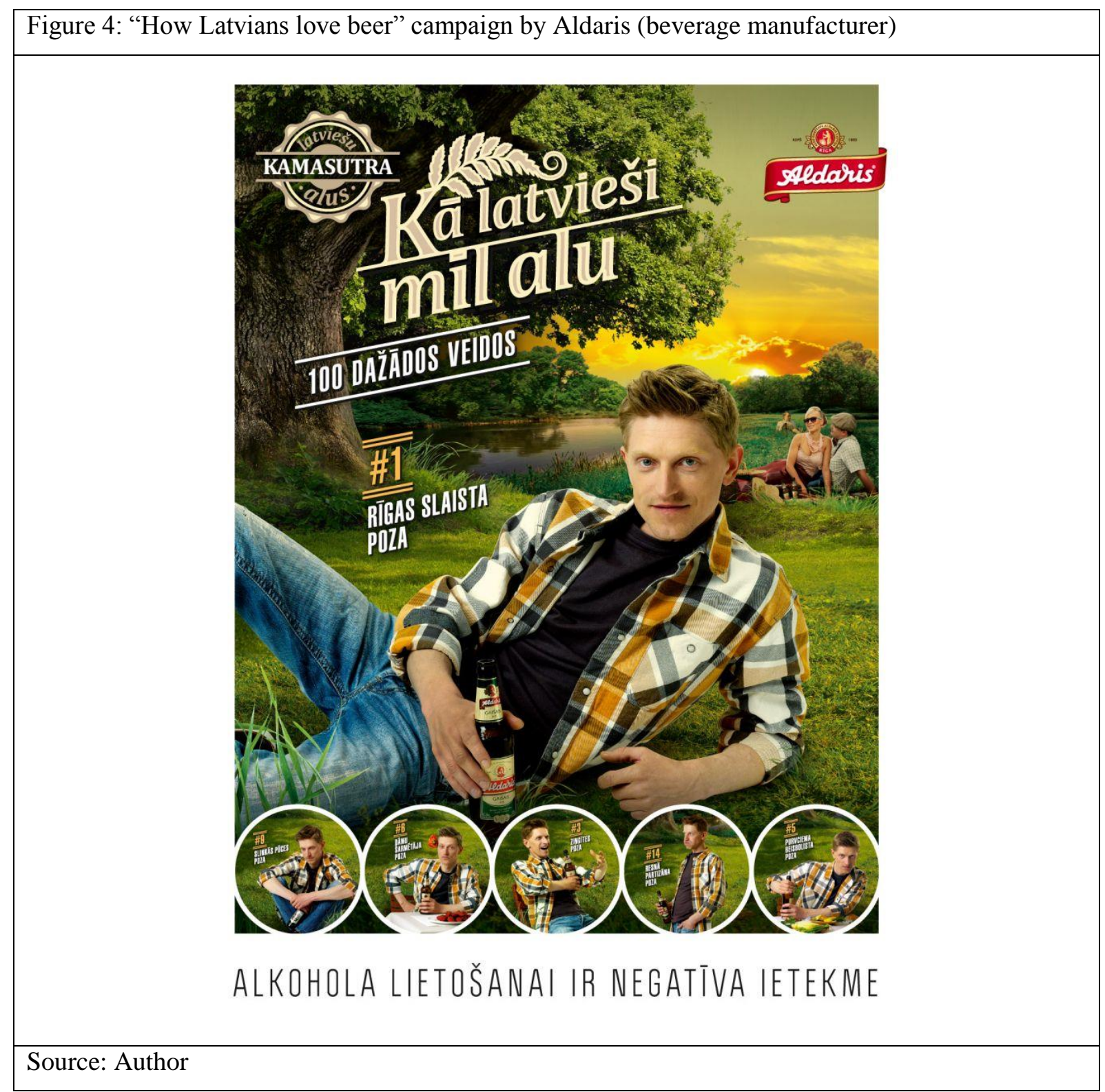

Here, we have a picture of a young man, and behind him we see a young couple. The young man is grinning, and has a bottle of beer in his hands. The colors used in this ad are light and pleasant. The bright colors attract the viewers' attention and this encourages the viewers to read the ad. The ad provides a sense of romance to the viewer. In the top corner of the picture is company's logo, in red and white. Also at the top of the picture, above the young man in the image, are the words: "Latvian beer Kamasutra. How Latvians love a beer in 100 different positions. \#1 - Run about of Riga." The discourse of this ad is about lifestyle, and is a reminder of traditional ways. Therefore, the viewer has the power to choose the beer or not; there is no sense of obligation. 


\section{Conclusion}

The purpose of this study was to analyze varying advertisements, both product and non-product ads, in order to see when the producers use their power to imply something to the viewer. The analysis showed us that it is very modern to use social discourse for commercial ads. The technique allows producers to improve relationships between viewers (consumers) and companies. In this case, we referred to the power in discourse as a form of social practice in various ways. The power behind discourse describes the formation of an order of social practices, which are themselves shaped and constituted by power relationships. By analyzing these advertisements and defining the position of the viewers, the following was concluded: the producers try to show the viewer that they have the power to either choose or not choose something.

The ideology behind the images used in the advertisements could be: that powerful people should show their power, so that the powerless might follow them (van Dijk, 2006). As a whole, it could be seen that producers use their power and ideology to change the behavior and thought of people. In any case, even as people become aware of this influence, they may become more submissive, because they can imagine themselves in the offered situations. This outcome may change as the narrative behind the situation becomes increasingly recognizable.

So, we can say that the socio-historical conditions that govern these processes of production and reception are controlling. Interpretations of this power will be as effective as how accurately we speak to the viewer.

\section{References}

Carroll, A. B. (1991). The pyramid of corporate social responsibility: Toward the moral management of organizational stakeholders. Business Horizons, 34(4), 39-48. doi: 10.1016/0007-6813(91)90005-G

Cook, G. (1992). The discourse of advertising London and New York: Routledge.

De Bono, E. (1985). Six Thinking Hats. New York: Little, Brown \& Co.

Fairclough, N. (1989). Language and Power. London: Longman.

Fairclough, N. (1995). Critical discourse analysis: The critical study of language. New York: Longman.

Ferrell, O. C., \& Hartline, M. (2012). Marketing Strategy, Text and Cases. South Western: Cengage Learning.

Gee, J. P. (2005). An Introduction to critical discourse analysis. Theory and method (2nd ed.). London and New York: Routledge.

Hall, S. (1973). Encoding and decoding in the television discourse. Paper presented at the the council of Europe Colloquy on "Training in the critical reading of television language", Organized by the Council \& The Centre for Mass Communication Research, University of Leicester.

Hatim, B., \& Mason, I. (1990). Discourse and the Translator London and New York: Longman.

Johnson-Laird, P. N. (2004). The history of mental models. In K. Manktelow \& M. C. Chung (Eds.), Psychology of reasoning: Theoretical and historical perspectives (pp. 179212). New York, NY: Psychology Press.

Kelly, A., Lawlor, K., \& O'Donohoe, S. (2009). Chapter 8 - Encoding Advertisements: The Creative Perspective. In J. Turow \& M. P. McAllister (Eds.), The Advertising and Consumer Culture Reader (pp. 133-149). New York: Routledge.

Kress, G. R., \& Van Leeuwen, T. (1996). Reading images. The grammar of visual design. London: Routledge.

Maignan, I., Gonzalez-Padron, T. L., Tomas, G., Hult, M., \& Ferrell, O. C. (2011). Stakeholder orientation: Development and testing of a framework for socially responsible marketing. Journal of Strategic Marketing, 19(4), 313-338.

Mothersbaugh, D., Huhmann, B., \& Franke, G. (2002). Combinatory and separative effects of rhetorical figures on consumers' effort and focus in ad processing. Journal of Consumer Research, 28(March), 589-602.

Nooyi, I. (2007). The responsible company. Retrieved from http://www.economist.com/node/10094800

Rayport, J. F. (2013). Advertising's New Medium: Human Experience. Harvard Business Review 91(3), 76-84.

Rayport, J. F., \& Jaworski, B. J. (2005). Best Face Forward: Why Companies Must Improve Their Service Interfaces With Customers. Boston, MA: Harvard Business School Press. 
CBU INTERNATIONAL CONFERENCE ON INNOVATION, TECHNOLOGY TRANSFER AND EDUCATION MARCH 25-27, 2015, PRAGUE, CZECH REPUBLIC

WWW.CBUNI.CZ, OJS.JOURNALS.CZ

Ries, A., \& Trout, J. (2001). Positioning: The Battle for Your Mind: The Battle for Your Mind. New York, NY: McGraw-Hill Education.

van Dijk, T. A. (2006). Discourse and manipulation. Discourse \& Society, 17(3), 359-383. doi: 10.1177/0957926506060250

Wodak, R. (Ed.). (1997). Gender and Discourse. Gender and Discourse. London: SAGE Publications Ltd. 